\title{
EVALUASI PROGRAM MODEL CIPP PADA PROSES PEMBELAJARAN IPA
}

\author{
Yoga Budi Bhakti \\ Universitas Indraprasta PGRI Jakarta \\ E-mail: bhaktiyoga.budi@gmail.com
}

\begin{abstract}
Abstrak
Tujuan penelitian ini untuk mengetahui penerapan evaluasi model CIPP (Contexs, Input, Prosess, Product), mengetahui hasil belajar siswa pada bidang studi IPA dan mengetahui keefektifan proses pembelajaran IPA dengan menggunakan evaluasi model CIPP di SMP IT Raudlatul Jannah. Penentuan keefektifan suatu proses pembelajaran dilihat dari seberapa besar tingkat ketercapaian tujuan pembelajaran yang telah ditentukan pada awal pembelajaran. Penelitian ini merupakan penelitian kualitatif yang menggunakan model CIPP dengan mengevaluasi tiap komponen konteks, input, proses dan produk untuk mencapai proses pembelajaran yang efektif. Sumber data penelitian adalah Guru IPA, wakil bidang kurikulum, serta Kepsek yang berada di SMP IT Raudlatul Jannah. Pengumpulan data primer menggunakan instrumen observasi sedangkan data sekunder diperoleh melalui dokumentasi dan wawancara. Data hasil observasi yang diperoleh kemudian dianalisis secara kuantitatif sedangkan data hasil dokumentasi dan wawancara dianalisis secara deskriptif kualitatif. Dari hasil penelitian menunjukkan pelaksanaan pembelajaran yang meliputi persyaratan pelaksanaan pembelajaran dan kegiatan pembelajaran dinyatakan cukup efektif.
\end{abstract}

Kata kunci: Evaluasi, CIPP, Proses, Pembelajaran, IPA.

\section{PENDAHULUAN}

Pendidikan pada hakikatnya merupakan kebutuhan dan tuntunan yang signifikan untuk menjamin perkembangan dan kelangsungan kehidupan bangsa dan negara demi tercapainya sumber daya manusia yang berintelektualitas dan berkualitas tinggi. Intelektualitas dan kualitas tersebut sangat bergantung dari keberhasilan penyelenggaraan sistem pendidikan. Setiap bangsa akan maju karena pendidikannya, pendidikan maju merupakan jantung dan denyut nadi bangsa. Dimana pendidikan nasional berfungsi mengembangkan kemampuan dan membentuk watak serta peradaban bangsa yang bermartabat dalam rangka mencerdaskan kehidupan bangsa, tujuan untuk berkembangnya potensi peserta didik agar menjadi manusia yang beriman dan bertakwa kepada Tuhan Yang Maha Esa, berakhlak mulia, kreatif, mandiri dan menjadi warga negara yang demokratis serta bertanggungjawab.
Dalam sutau proses belajar mengajar terdapat kegiatan evaluasi. Evaluasi adalah suatu kegiatan untuk mengetahui apakah proses belajar mengajar itu telah mencapai tujuan yang sudah ditetapkan atau belum, dengan kata lain proses belajar mengajar belum diketahui berhasil tidaknya sebelum evaluasi dilakukan. Karena itu evaluasi harus diperlukan dalam proses belajar mengajar. Dengan evaluasi yang baik, dan menyeluruh akan dapat mengetahui apa yang diinginkan dari kegiatan belajar mengajar. Suatu evaluasi dikatakan baik jika mempunyai kriteria-kriteria. Adapun kriteria evaluasi itu baik menurut Smith (2002) adalah "validitas, Obyektifitas, Prakticability". Dari evaluasi yang baik itulah akan dapat memberi motivasi baik kepada siswa maupun kepada guru. Dalam ilmu evaluasi pendidikan, ada banyak model yang bisa digunakan untuk mengevaluasi suatu program. Meskipun antara satu dengan lainnya berbeda, namun maksudnya sama yaitu melakukan kegiatan pengumpulan data atau informasi yang berkenaan dengan obyek yang 
dievaluasi, yang tujuannya menyediakan bahan bagi pengambil keputusan dan menetukan tindak lanjut suatu program.

Model evaluasi muncul karena adanya usaha secara kontinyu yang diturunkan dari perkembangan pengukuran dan keingintahuan manusia untuk berusaha menerapkan prinsip evaluasi pada cakupan yang lebih abstrak termasuk pada bidang ilmu pendidikan, perilaku, dan seni (Stufflebeam, 1971a). Evaluasi selalu memegang peranan yang penting dalam segala bentuk pengajaran yang efektif. Dengan evaluasi diperoleh balikan yang dipakai untuk memperbaiki bahan atau metode pengajaran atau untuk menyesuaikan bahan dengan perkembangan ilmu pengetahuan. Menurut Stufflebeam (1971b) mengatakan bahwa:"dari tiga aspek (kognitif, afektif, dan psikomotor) jika dikaitkan dengan proses pembelajaran maka evaluasi hasil belajar itu hendaknya bukan hanya mengungkapkan pemahaman peserta didik terhadap materi pelajaran. Melainkan juga harus dapat mengungkapkan sejauh mana peserta didik dapat memahami dan mengaplikasikan materi pelajaran tersebut dalam kehidupan seharihari.

Prestasi belajar merupakan bukti utama dari keberhasilan belajar siswa didalam menuntut ilmu baik melalui pendidikan formal, non formal dan informal. Untuk mencapai suatu hasil belajar tidak terlepas dari proses belajar mengajar. Adapun dalam proses belajar mengajar banyak dipengaruhi oleh faktor pendidik, anak didik, kurikulum, alat dan faktor lingkungan.

Untuk mengetahui tercapai tidaknya

tujuan khusus pembelajaran guru perlu mengadakan evaluasi model CIPP (Contexs, Input, Prosess, Product). Karena penilaian ini untuk mengetahui sejauh mana peserta didik telah menguasai tujuan khusus pembelajaran yang ingin dicapai oleh sebab itu seorang guru hendaknya secara terus menerus mengikuti hasil belajar yang telah dicapai oleh peserta didiknya. Informasi yang diperoleh dari evaluasi model CIPP ini merupakan umpan balik terhadap proses hasil belajar megajar yang telah dilaksanakan dan umpan balik ini akan menjadi tolok ukur untuk memperbaiki dan meningkatkan proses belajar mengajar selanjutnya.
Mengingat evaluasi merupakan upaya untuk memperoleh informasi tentang perolehan belajar siswa secara menyeluruh baik pengetahuan, sikap maupun keterampilan. Maka dalam efektifitas evaluasi model CIPP dalam proses pembelajaran sangat dibutuhkan.

Dari uraian permasalahan tersebut diatas maka dapat dirumuskan permasalahan yang secara logika dan dapat dipandang sebagai suatu masalah dan harus dicari jawabannya melalui penelitian sebagai berikut:

1. Bagaimana penerapan evaluasi model CIPP (Contexs, Input, Prosess, Product) dalam pembelajaran IPA?

2. Bagaimana hasil belajar siswa pada bidang studi IImu Pengetahuan Alam?

3. Bagaiamana efektifitas proses pembelajaran menggunakan evaluasi model CIPP (Contexs, Input, Prosess, Product) terhadap hasil belajar siswa pada bidang studi IImu Pengetahuan Alam?akhir Anda adalah untuk membuat makalah yang sesuai dengan aturan baku jurnal JIPFRI. Untuk hal-hal yang tidak tercantum di panduan ini, silahkan mengacu pada informasi yang telah Anda dapatkan pada aturan penulisan ilmiah.

\section{METODE/EKSPERIMEN}

Penelitian ini dilaksanakan pada SMP IT Raudlatul Jannah. Kelas yang digunakan untuk penelitian kelas 7 dalam mata pelajaran IImu Pengetahuan Alam (IPA). Jenis penelitian evaluasi pembelajaran IImu Pengetahuan Alam menggunakan model CIPP ini merupakan penelitian dengan pendekatan kualitatif. Dari data yang terkumpul, kemudian dideskripsikan dalam bentuk naratif. Miles dan Huberman (1994) mengatakan bahwa analisis data dalam riset kualitatif merupakan proses yang terus menerus dilakukan dengan observasi non partisipan. Sehingga metode analisis data yang digunakan dalam penelitian ini dilakukan sepanjang penelitian berlangsung, dimulai dari observasi awal, pengumpulan data, tahap penulisan laporan sampai pada penarikan kesimpulan. Yang kemudian hasilnya di narasikan.

Metode analisis pada instrumen yang dibuat adalah dengan cara validasi oleh ahli. 
Dalam hal ini penilaian oleh validator terhadap instrumen didasarkan pada indikator-indikator yang termuat dalam Lembar Validasi setiap instrumen. Penilaian pada lembar valiadasi berupa penskoran dari 1-4, dengan setiap skor memiliki indikator ketercapaian berbeda-beda.

Metode yang digunakan dalam pengumpulan data-data menurut Creswell (1998), yaitu:

a. Metode observasi: metode ini dilakuakan menggunakan instrumen, yang berupa lembar pengamatan dan kuisioner/angket dalam pelaksanan evaluasi pembelajaran IImu Pengetahuan Alam menggunakan metode CIPP.

b. Metode wawancara: sebelum dilakukan wawancara terhadap subjek penelitian, peneliti menyiapkan kerangka pertanyaan dalam pelaksanan evaluasi pembelajaran IImu Pengetahuan Alam menggunakan metode CIPP. Metode ini digunakan untuk memperjelas hasil observasi sehingga permasalahan dapat terlihat secara mendalam dan detail.

c. Metode diskusi dan dokumentasi: metode ini digunakan untuk mencari data mengenai hal-hal atau variable yang berupa catatan, buku, surat kabar, majalah, agenda, dan sebagainya.

\section{Tahapan monitoring dan evaluasi}

Fokus monitoring dan evaluasi berdasarkan tahapan monitoring dan evaluasi Context-Input-Process-Product dikemukakan oleh Stufflebeam (2007) sebagai berikut:

1. Penilaian konteks meliputi profil sekolah, latar belakang program pembelajaran sekolah, faktor geografis-demografis, dan latar belakang sosial ekonomi dan pendidikan orang tua siswa. Informasi yang dikumpulkan digunakan sebagai dasar dalam pertimbangan program.

2. Penilaian input meliputi peserta didik, kurikulum, bahan ajar, dan guru serta sarana belajar. Data dikumpulkan selama tahap penilaian digunakan sebagai pengambil keputusan.

3. Penilaian proses adalah kegiatan penilaian selama pelaksanaan pembelajaran. Penilaian ini berkaitan langsung dengan, aktivitas belajar, penggunaan media pembelajaran, kemanfaatan laboratorium, dan pemberian jenis tugas.

4. Penilaian produk/output, berhubungan dengan hasil pelaksanaan program. Penilaian dilakukan untuk mengetahui sampai seberapa jauh pelaksanaan pembelajaran IPA di kelas telah berhasil mencapai tujuan berdasarkan kriteria yang ditetapkan, yang meliputi hasil belajar peserta didik dan nilai rerata.

Dasar kegiatan dalam evaluasi program pelaksanaan pembelajaran IPA ini melalui tahapan-tahapan konteks, input, proses dan produk. Penggunaan model CIPP dalam evaluasi program ini karena:

a. Dengan model CIPP, maka kegiatan evaluasi pelaksanaan pembelajaran IPA dapat dilakukan perbandingan yang mendasar antara data di lapangan dengan standar yang ditentukan.

b. Dapat membuat evaluasi dan penilaian tentang pelaksanaan pembelajaran IPA dilihat dari indikator konteks, input, proses dan produk/output.

c. Dengan model CIPP, indikator konteks, input, proses dan produk/output yang dibandingkan tidak hanya untuk menentukan apakah ada perbedaan tujuan dengan keadaan sebenarnya, tetapi juga dibandingkan dengan standar yang ditentukan.

Untuk memudahkan monitoring evaluasi, maka perlu dilihat indikator indikator yang terdapat dalam konteks, input, proses dan output yang digunakan dalam monitoring evaluasi ini, yaitu: 
Tabel 1. Sumber Data Evaluasi Program Pembelajaran IPA

\begin{tabular}{|c|c|c|c|c|}
\hline Komponen & Aspek & Indikator & $\begin{array}{l}\text { Sumber } \\
\text { Data }\end{array}$ & $\begin{array}{c}\text { Instrumen } \\
\text { Pengumpul } \\
\text { Data }\end{array}$ \\
\hline Konteks & $\begin{array}{l}\text { Profil tempat } \\
\text { belajar }\end{array}$ & $\begin{array}{l}\text { Nama Sekolah,Jumlah Rombel, Jumlah } \\
\text { Guru, Jumlah Siswa, Jadwal Pelajaran, } \\
\text { Ketersedian Sarana Prasarana Belajar, } \\
\text { Kualifikasi Guru Mata Pelajaran }\end{array}$ & Kepsek & $\begin{array}{l}\text { Pedoman } \\
\text { wawancara } \\
\text { Pedoman } \\
\text { Observasi } \\
\text { Analisis } \\
\text { Dokumen }\end{array}$ \\
\hline \multirow[t]{5}{*}{ Input } & Peserta didik & $\begin{array}{l}\text { Jumlah peserta didik, jumlah calon } \\
\text { peserta didik, latar belakang peserta } \\
\text { didik }\end{array}$ & Kepsek & $\begin{array}{l}\text { Pedoman } \\
\text { Angket }\end{array}$ \\
\hline & Kurikulum & Kurikulum yang digunakan & Kepsek & $\begin{array}{l}\text { Pedoman } \\
\text { Angket }\end{array}$ \\
\hline & Bahan ajar & Bahan ajar yang digunakan & $\begin{array}{l}\text { Guru } \\
\text { Bidang } \\
\text { Studi }\end{array}$ & $\begin{array}{l}\text { Pedoman } \\
\text { Angket }\end{array}$ \\
\hline & Guru & $\begin{array}{l}\text { Jumlah guru Bidang Studi IPA dan } \\
\text { Kualifikasinya }\end{array}$ & $\begin{array}{l}\text { Guru } \\
\text { Bidang } \\
\text { Studi }\end{array}$ & $\begin{array}{l}\text { Pedoman } \\
\text { Angket }\end{array}$ \\
\hline & Sarana belajar & $\begin{array}{l}\text { Ruang tempat belajar, ruang } \\
\text { perpustakaan, laboratorium }\end{array}$ & $\begin{array}{l}\text { Tempat } \\
\text { Belajar }\end{array}$ & $\begin{array}{l}\text { Pedoman } \\
\text { Observasi }\end{array}$ \\
\hline \multirow[t]{7}{*}{ Proses } & $\begin{array}{l}\text { Pelaksanaan dan } \\
\text { aktivitas } \\
\text { pembelajaran }\end{array}$ & $\begin{array}{l}\text { Belajar mandiri, diskusi antar peserta } \\
\text { didik, diskusi peserta didik dengan guru } \\
\text { bidang studi }\end{array}$ & $\begin{array}{l}\text { Tempat } \\
\text { belajar } \\
\text { Guru }\end{array}$ & $\begin{array}{l}\text { Pedoman } \\
\text { observasi } \\
\text { Pedoman } \\
\text { angket }\end{array}$ \\
\hline & $\begin{array}{l}\text { Penggunaan media } \\
\text { pembelajaran }\end{array}$ & $\begin{array}{l}\text { Buku Pelajaran, video pembelajaran, } \\
\text { audio pembelajaran, Proyektor, Media } \\
\text { Presentasi Power Point, Software } \\
\text { Pembelajaran }\end{array}$ & $\begin{array}{l}\text { Tempat } \\
\text { belajar }\end{array}$ & $\begin{array}{l}\text { Pedoman } \\
\text { observasi }\end{array}$ \\
\hline & & & Guru & $\begin{array}{l}\text { Pedoman } \\
\text { Angket }\end{array}$ \\
\hline & $\begin{array}{l}\text { Kemanfaatan } \\
\text { laboratorium dan } \\
\text { perpustakaan }\end{array}$ & $\begin{array}{l}\text { Penggunaan laboratorium, Jadwal } \\
\text { Penggunaan Laboratorium, Jumlah } \\
\text { Kunjungan Siswa ke Perpustakaan, } \\
\text { Jumlah Koleksi Buku IPA }\end{array}$ & $\begin{array}{l}\text { Tempat } \\
\text { Belajar } \\
\text { Peserta } \\
\text { Didik }\end{array}$ & $\begin{array}{l}\text { Pedoman } \\
\text { observasi }\end{array}$ \\
\hline & & & & $\begin{array}{l}\text { Pedoman } \\
\text { Angket }\end{array}$ \\
\hline & $\begin{array}{l}\text { Pemberian jenis } \\
\text { tugas }\end{array}$ & $\begin{array}{l}\text { Tugas mandiri, Tugas Kelompok, Tugas } \\
\text { Proyek, Latihan Mandiri }\end{array}$ & $\begin{array}{l}\text { Peserta } \\
\text { Didik }\end{array}$ & $\begin{array}{l}\text { Pedoman } \\
\text { Angket }\end{array}$ \\
\hline & Administrasi Guru & $\begin{array}{l}\text { Menyusun RPP, Mengoreksi tugas dan } \\
\text { ulangan siswa, Membuat Jadwal Ujian, } \\
\text { Membuat bahan ajar, Melakukan } \\
\text { Penilaian }\end{array}$ & Guru & $\begin{array}{l}\text { Pedoman } \\
\text { Angket }\end{array}$ \\
\hline Produk & $\begin{array}{l}\text { Hasil belajar } \\
\text { peserta didik }\end{array}$ & $\begin{array}{l}\text { Hasil belajar tes harian, tes mid } \\
\text { semester, tes akhir semester }\end{array}$ & Guru & $\begin{array}{l}\text { Analisis } \\
\text { Dokumen }\end{array}$ \\
\hline
\end{tabular}


Berikut disajikan tabel aspek dan kriteria evaluasi.

Tabel 2. Aspek dan Kriteria Evaluasi Program Pembelajaran IPA

\begin{tabular}{|c|c|c|}
\hline $\begin{array}{l}\text { Variabel/Objek } \\
\text { Penelitian }\end{array}$ & Aspek yang Dievaluasi & Kriteria Keberhasilan \\
\hline Peserta Didik & $\begin{array}{ll}\text { - } & \text { Pembelajaran di Laboratorium } \\
\text { - } & \text { Penggunaan Perpustakaan Sebagai } \\
& \text { Sumber Belajar }\end{array}$ & $\begin{array}{ll}\text { - } & \text { Adanya Kegiatan Belajar di } \\
\text { Laboratorium } \\
\text { - } \\
\begin{array}{l}\text { Adanya data Jumlah Kunjungan Siswa } \\
\text { ke Perpustakaan }\end{array} \\
\end{array}$ \\
\hline Kurikulum & $\begin{array}{ll} & \text { Dokumen Kurikulum } \\
- & \text { Silabi pembelajaran IPA } \\
\text { - } & \text { RPP Pembelajaran IPA buatan Guru }\end{array}$ & $\begin{array}{l}\text { - } \text { Terdapat dokumen kurikulum, silabus } \\
\text { pembelajaran IPA dan RPP } \\
\text { Pembelajaran IPA buatan Guru }\end{array}$ \\
\hline $\begin{array}{ll}\text { Kegiatan } & \text { Belajar } \\
\text { Mengajar } & \end{array}$ & $\begin{array}{lll}\text { - } & \text { Kesesuaian materi dengan } \\
& \text { kompetensi yang diajarkan } \\
\text { - } & \text { Kesesuain materi dengan } \\
& \text { kompetensi yang diajarkan } \\
\text { - } & \text { Persiapan Mengajar } \\
\text { - } & \text { Interaksi dalam pembelajaran } \\
\text { - } & \begin{array}{l}\text { Penggunaan } \\
\text { pembelajaran media/modul }\end{array} \\
\end{array}$ & $\begin{array}{ll}\text { - } & \text { Ada hasil kesesuaian materi dengan } \\
& \text { kompetensi yang diajarkan } \\
\text { - } & \text { Adanya RPP } \\
\text { - } \quad \text { Terdapat Interaksi saat pembelajaran } \\
\text { - Guru menggunakan media/modul } \\
\text { pembelajaran }\end{array}$ \\
\hline $\begin{array}{lr}\text { Penilaian } & \text { hasil } \\
\text { belajar } & \text { peserta } \\
\text { didik } & \end{array}$ & - Penilaian sumatif dan formatif & $\begin{array}{l}\text { - Adanya hasil penilian sumatif dan } \\
\text { formatif }\end{array}$ \\
\hline $\begin{array}{l}\text { Fasilitas } \\
\text { Pendidikan }\end{array}$ & $\begin{array}{llll}\text { Buku Pelajaran dan } & \text { Media } \\
& \text { Pembelajaran }\end{array}$ & $\begin{array}{ll}\text { - } & \text { Adanya Buku Pelajaran dan Media } \\
\text { Pembelajaran }\end{array}$ \\
\hline Tenaga Pendidik & $\begin{array}{l}\text { Membuat RPP, Media Pembelajaran, } \\
\text { Melakukan evaluasi, Mengadakan Ujian, } \\
\text { Memberikan Tugas }\end{array}$ & $\begin{array}{l}\text { Guru Melakukan Tugas Berupa Membuat } \\
\text { RPP, Media Pembelajaran, Melakukan } \\
\text { evaluasi, Mengadakan Ujian, Memberikan } \\
\text { Tugas }\end{array}$ \\
\hline Hasil belajar & $\begin{array}{l}\text { Penilaian untuk mengetahui hasil } \\
\text { belajar peserta didik meliputi : Tes } \\
\text { harian, Tes tengah semester, Tes akhir } \\
\text { semester }\end{array}$ & $\begin{array}{l}\text { Adanya Penilaian untuk mengetahui hasil } \\
\text { belajar peserta didik meliputi : Tes harian, } \\
\text { Tes tengah semester, Tes akhir semester }\end{array}$ \\
\hline
\end{tabular}

\section{HASIL DAN PEMBAHASAN}

\section{Komponen Konteks Program Pembelajaran IPA}

Evaluasi konteks dalam program pembelajaran IPA dimulai dari profil tempat pembelajaran dilaksanakan. Tempat pembelajaran bernama SMP IT Raudlatul Jannah yang berlokasi di Jl. Nurul Aini S. Gatam, Banjarwangi, Ciawi Bogor. SMP IT Raudlatul Jannah dibawah naungan LPIT Raudlatul Jannah, Selain SMP IT terdapat juga TK IT, SD IT Raudlatul Jannah.

Jumlah rombongan belajar pada SMP IT adalah 9 kelas paralel, yang masing-masing tingkat berjumlah 3 kelas, dimana setiap kelas terdiri dari 25 peserta didik. Total jumlah peserta didik di SMP IT Raudlatul Jannah berjumlah 225 peserta didik. Sedangkan jumlah gurunya adalah 18 orang, dimana untuk guru bidang studi Ilmu Pengetahuan Alam berjumlah 2 orang guru.

Bentuk fisik bangunan SMP IT Raudlatul Jannah layak untuk menyelenggarakan pendidikan. Ruangan yang terdapat di SMP IT adalah 9 ruang kelas, 1 perpustakaan, 1 Laboratorium IPA, 1 Ruang Guru, 1 Ruang Kepala Sekolah, 1 Ruang Wakil Kepala Sekolah, 1 Ruang Direktur LPIT, Aula, Masjid, Kantin dan Lahan Parkir kendaraan. Dimana setiap ruang kelas sudah terdapat infocus dan proyektor yang sangat mendukung dalam proses pembelajaran.

Komponen Input Program Pembelajaran IPA

Sajian aspek input dalam penelitian evaluasi ini meliputi: (1) peserta didik yang 
mengikuti pendidikan di SMP IT Raudlatul Jannah, (2) kurikulum, (3) bahan ajar, (4) guru, dan (5) sarana dan prasarana belajar.

1. Peserta Didik. Hasil evaluasi mengenai peserta didik yang mengikuti pendidikan di SMP IT Raudlatul Jannah untuk tahun ajaran 2016/2017 adalah sebanyak 225 peserta didik.

2. Kurikulum. Dari hasil evaluasi yang dilakukan, ditemukan bahwa kurikulum yang digunakan di SMP IT Raudlatul Jannah menggunakan kurikulum 2013, secara umum meliputi mata pelajaran: (1) Pendidikan Agama, (2) PKn, (3) Seni Budaya, (4) Pendidikan Jasmani, (5) Bahasa Indonesia , (6) Bahasa Inggris, (7) Matematika, (8) IPA, (9) IPS, (10) Muatan Lokal.

3. Bahan Ajar. Dari hasil evaluasi ditemukan bahwa bahan ajar utama di SMP IT Raudlatul Jannah adalah bahan ajar cetak berupa buku pelajaran, yang dirancang oleh pemerintah sehingga dapat dipelajari peserta didik secara mandiri. Selain buku cetak, di SMP IT Raudlatul Jannah juga dikembangkan bahan ajar penunjang seperti program audio, video/VCD, Presentasi Power point, Pesona IPA dan media lainnya yang dirancang secara khusus oleh Pustekkom.

4. Guru. Guru yang terdapat di SMP IT Raudlatul Jannah terdiri dari 18 orang guru, sedangkan untuk guru bidang studi IPA terdapat 2 orang guru. satu orang guru lakilaki dan satu orang guru perempuan. Semua guru subjek telah berstatus Guru tetap yayasan yang sudah dapat sertifikasi guru dan mempunyai latar belakang Pendidikan Fisika dan Pendidikan Biologi. Pengalaman mengajar guru bervariasi, minimum 8 tahun dan maksimum 10 tahun dan mempunyai pengalaman mengikuti pelatihan/penataran yang berkaitan dengan materi pembelajaran, silabus, dan sistem penilaian IPA hampir sama selama dua tahun terakhir. Semua guru subjek mengikuti penataran yang dilaksanakan oleh MGMP tentang materi pembelajaran, penilaian pembelajaran serta penelitian tindakan kelas.

\section{Sarana Belajar}

Ruang Tempat Belajar. Hasil evaluasi menunjukkan bahwa ruang belajar yang digunakan oleh SMP IT Raudlatul Jannah secara keseluruhan adalah bangunan sekolah (100\%). Dan semua kelas sudah terpasang infokus dan proyektor, sehingga untuk ketersediaan ruang belaj ar beserta sarana prasarananya mencukupi dan layak digunakan.

Ruang Perpustakaan. Hasil monitoring evaluasi menunjukkan bahwa ketersediaan ruang perpustakaan di SMP IT Raudlatul Jannah cukup memadai. Jumlah kunjungan perpustakaan terekam secara terstruktur, jumlah koleksi buku yang mendukung pembelajaran di sekolah cukup memadai.

Laboratorium. Ketersediaan laboratorium di SMP IT Raudlatul Jannah yang dimaksud adalah laboratorium IPA. Hasil evaluasi menunjukkan bahwa keberadaan laboratorium tersebut digunakan untuk mendukung pembelajaran IPA, dibuktikan dengan adanya jadwal serta data pemakaian/peminjaman barang di laboratorium.

\section{Komponen Proses Program Pembelajaran IPA}

Standar pelaksanaan pembelajaran yang digunakan dalam penelitian ini adalah Standar Proses yang tercantum pada PP. 41 tahun 2007. Pelaksanaan pembelajaran merupakan implementasi dari Rencana Pelaksanaan Pembelajaran yang telah dibuat sebelumnya. Proses pelaksanaan pembelajaran terbagi menjadi dua bagian penting, yaitu persyaratan pelaksanaan pembelajaran dan pelaksanaan pembelajaran itu sendiri.

\section{Persyaratan Pelaksanaan Pembelajaran}

Data persyaratan pembelajaran diperoleh dengan wawancara kepada guru, wakil bidang kurikulum dan kepala sekolah serta didukung data dokumentasi. Persyaratan yang pertama adalah jumlah rombongan belajar, rombongan belajar adalah jumlah peserta didik yang terdapat di dalam satu kelas. Jumlah siswa setiap rombongan belajar di SMP IT Raudlatul Jannah adalah 25 peserta didik setiap kelas, sedangkan standar rombongan belajar untuk SMP/MTS adalah 32 peserta didik setiap kelas. Dari data tersebut maka kesenjangan yang 
terjadi antara standar dan kenyataan di lapangan tidak terlalu besar namun diperlukan pengurangan atau penambahan jumlah peserta didik pada sekolah agar sesuai dengan standar baku.

Prasyarat yang kedua adalah beban kerja minimal guru. Beban kerja guru mencakup kegiatan pokok yaitu merencanakan pembelajaran, melaksanakan pembelajaran, menilai hasil pembelajaran, membimbing dan melatih peserta didik, serta melaksanakan tugas tambahan. Perencanaan pembelajaran yang dilakukan oleh guru meliputi pembuatan Silabus, Rencana Pelaksanaan Pembelajaran, program tahunan, program semester, dan distribusi alokasi waktu.

Buku teks yang dimiliki oleh masingmasing sekolah subjek untuk mata pelajaran IPA sudah terpenuhi dengan perhitungan satu buku per satu siswa, dengan pertimbangan mata pelajaran IPA merupakan salah satu mata pelajaran UN. Penggunaan buku paket ini bersamaan dengan LKS yang telah dimilikii siswa. Pengelolaan kelas dilakukan sebelum dan ketika pembelajaran berlangsung sesuai dengan metode pembelajaran yang dipakai serta disesuaikan dengan materi yang akan di bahas.

Dari hasil pembahasan diatas dapat disimpulkan bahwa persyaratan pembelajaran yang ada di sekolah dapat dikategorikan cukup efektif dengan adanya kelengkapan prasyarat jumlah rombongan belajar, beban kerja guru yang tidak terlalu berat, jumlah buku panduan yang mencukupi serta pengelolaan kelas yang lengkap dan terorganisasi dengan baik.

\section{Proses Pelaksanaan Pembelajaran}

Dari hasil observasi aspek pelaksanaan pembelajaran diperoleh data yang tercantum pada Tabel 3.

Dari tabel tersebut dapat dilihat bahwa dalam semua aspek pelaksanaan pembelajaran mendapat skor lebih dari 3,0. Menurut pedoman penskoran yang telah dibuat sebelumnya maka dapat ditentukan bahwa dalam aspek pelaksanaan pembelajaran ini memenuhi kriteria cukup efektif.

Tabel 3. Nilai Keefektifan Pelaksanaan Pembelajaran IPA di SMP IT Raudlatul Jannah

\begin{tabular}{|c|c|c|c|c|c|}
\hline \multirow[b]{2}{*}{ Komponen dan sub komponen penelitian } & \multirow{2}{*}{$\begin{array}{l}\text { Rerata } \\
\text { skor }\end{array}$} & \multicolumn{4}{|c|}{ Klasifikasi } \\
\hline & & $\begin{array}{c}\text { Tidak } \\
\text { efektif }\end{array}$ & $\begin{array}{c}\text { Kurang } \\
\text { efektif }\end{array}$ & $\begin{array}{l}\text { Cukup } \\
\text { efektif }\end{array}$ & Efektif \\
\hline \multicolumn{6}{|l|}{ Pelaksanaan Pembelajaran } \\
\hline mengelola ruang dan fasilitas pembelajaran & 3,6 & & & & $\mathbf{v}$ \\
\hline melaksanakan kegiatan pembelajaran & 3,0 & & & $\mathbf{v}$ & \\
\hline mengelola interaksi kelas & 3,1 & & & $\mathbf{v}$ & \\
\hline $\begin{array}{l}\text { bersikap terbuka dan luwes serta membentuk } \\
\text { mengembangkan sikap positif siswa terhadap } \\
\text { belajar }\end{array}$ & 3,2 & & & $\mathbf{v}$ & \\
\hline $\begin{array}{l}\text { Demo kemampuan khusus dalam pembelajaran } \\
\text { mata pelajaran tertentu }\end{array}$ & 3,3 & & & $\mathbf{v}$ & \\
\hline melaksanakan evaluasi proses dan hasil belajar & 3,3 & & & $\mathbf{v}$ & \\
\hline kesan umum kinerja guru & 3,1 & & & $\mathbf{v}$ & \\
\hline Jumlah & 3,2 & & & $\mathbf{v}$ & \\
\hline
\end{tabular}




\section{Komponen Produk Program Pembelajaran IPA}

Sajian aspek produk/output pada hasil penelitian ini meliputi pencapaian hasil belajar peserta didik SMP IT Raudlatul Jannah pada tes ualngan harian, ulangan tengah semester dan ulangan akhir semester. Dari hasil evaluasi komponen produk dapat dinyatakan hasil belajar peserta didik baik ulangan harian, tengah semester dan akhir semseter yang mencapai standar kriteria ketuntasan minimal 70 terdapat $76 \%$ atau sekitar 171 peserta didik. Hasil ini dapat menunjukkan bahwa proses pembelajaran IPA di SMP IT Raudlatul Jannah cukup efektif jika ditinjau dari hasil belajar peserta didik.

\section{PENUTUP}

\section{Simpulan}

Pelaksanaan pembelajaran IPA di SMP IT Raudlatul Jannah cukup efektif dilihat dari aspek persyaratan pelaksanaan pembelajaran berupa jumlah rombongan belajar, beban kerja guru, jumlah buku teks yang dimiliki sekolah serta pengelolaan kelas yang lengkap dan terorganisasi dengan baik. Sedangkan pelaksanaan kegiatan pembelajaran di kelas dinyatakan cukup efektif dengan beberapa kekurangan yaitu pengelolaan waktu pembelajaran yang kurang maksimal untuk mancapai tujuan pembelajaran. Disamping itu, aspek pelaksanaan penilaian proses juga belum terlihat berjalan dengan lancar dan tepat pada sasaran.

\section{Saran}

$\begin{array}{rrr}\text { Proses pelaksanaan pembelajaran } & \text { peran oleh } \\ \text { sangat ditentukan beraturan } \\ \text { perencanaan pembelajaran baik yang }\end{array}$ dilakukan oleh guru maupun kurikulum. Penentuan jumlah rombongan belajar, beban kerja minimal guru, jumlah buku teks yang dipunyai dan pengelolaan kelas yang dilakukan oleh guru merupakan prasyarat penting mencapai tujuan pembelajaran. Oleh karena itu perlu diadakan sebuah kegiatan khusus sebagai upaya meningkatkan pemahaman guru terhadap proses pembelajaran.

\section{UCAPAN TERIMAKASIH}

Ucapan terima kasih penulis ucapkan kepada Lembaga Penelitian dan Pengabdian Kepada Masyarakat (LPPM) Universitas Indraprasta (Unindra) PGRI yang telah mendanai penelitian ini melalui program Hibah DIPA Unindra.

\section{DAFTAR PUSTAKA}

Creswell, J. W. (1998). Qualitative inquiry and research design: Choosing among five traditions. Thousand Oaks, CA: Sage Publications.

Miles, M.B., \& Huberman A.M. (1994). Qualitative data analysis: A sourcebook of new methods. Newbury Park, CA: Sage.

Smith, C. L., \& Freeman, R. L. (2002). Using continuous system level assessment to build school capacity. American Journal of Evaluation, 23(3), 307-319.

Stufflebeam, D. L. (1971a). The use of experimental design in educational evaluation. Journal of Educational Measurement, 8(4), 267-274.

Stufflebeam, D. L. (1971b). An EEPA interview with Daniel L. Stufflebeam. Educational Evaluation and Policy Analysis, 2(4), 85-90.

Stufflebeam, D. L. (2007). CIPP evaluation model checklist (2nd ed.). Retrieved fromhttp://www.wmich.edu/evalctr/arc hive checklists/cippchecklist mar2016 pdf 